\title{
Antimicrobial Property of Picrorhiza kurroa Against Multi-Drug Resistant Uropathogenic Escherichia coli
}



1 Department of Biotechnology, School of Basic and Applied Sciences, Shri Guru Ram Rai University, Patel Nagar, Dehradun, Uttarakhand, 248001, India; pavidheer14@gmail.com (P.D.);

2 Department of Pharmacovigilance, Paraxel International Pvt. Ltd., Mohali, Punjab, India; mohitpant97@gmail.com (M.P.);

3 Department of Biotechnology, I.K. Gujral Punjab Technical University, Jalandhar, Punjab 144603, India; siddharthadan7@gmail.com (S.D.);

4 Department of Biochemistry, Sai Institute of Paramedical and Allied Sciences, Dehradun, Uttarakhand, India; shilpasemwa1999@gmail.com (S.S.);

5 Department of Bioengineering, Birla Institute of Technology, Mesra, Ranchi, Jharkhand, India; rishabgaerg.aks@gmail.com (R.G.);

* Correspondence: rishabgaerg.aks@gmail.com (R.G.); shilpasemwal999@gmail.com (S.S.);

Scopus Author ID 57218994496

Received: 25.05.2021; Revised: 30.07.2021; Accepted: 3.08.2021; Published: 5.09.2021

\begin{abstract}
As per the current scenario of weakened immune systems in humans and inadequate usage of antibiotics, the infections came out as serious medical conditions and pathogens, especially bacteria causing urinary tract infections to have gained resistance. To combat this, the bioactive and antimicrobial properties of healing herbs have gained the limelight. Likewise, Picrorhiza kurroa, a famous traditional and local drug in the higher Himalayan region, is used for antimicrobial treatments and partial sanitation of air by the tribes, including Ayurveda scientists. This study was done on the urine sample of a 78-year-old UTI patient, the successive pathological tests revealed the acute infected condition, and further microbiological analysis of the urine sample diagnosed the presence of pathogenic E. coli in large numbers, which was further detected to be multiple drug-resistant (MDR) by antibiotic sensitivity tests. The plant extract through the methanol extraction method of Picrorhiza kurroa roots was subjected to antimicrobial assay against the isolated pathogen E. coli by well diffusion method. The MDR E. coli was found to be highly sensitive against the plant extract indicating $23 \mathrm{~mm}$ microbial inhibition zone, which proves the description of Kedar Jadi as an antimicrobial drug mentioned in Charak Samhita; furthermore, this can lead to the preparation of drugs and addition in combating against acute MDR bacterial infections.
\end{abstract}

Keywords: urinary tract infections (UTI); antibiotics; phytochemical; antimicrobial; multidrug resistant.

(C) 2021 by the authors. This article is an open-access article distributed under the terms and conditions of the Creative Commons Attribution (CC BY) license (https://creativecommons.org/licenses/by/4.0/).

\section{Introduction}

Urinary tract infections (UTI) are among the leading reasons for treatment in adult medical care medicine, accounting for substantial antibiotic prescriptions. Because this problem is so common so significant in routine clinical practice, a high level of diagnostic accuracy is important. Being caused by gram-negative bacteria like E. coli, Klebsiella sp., Enterobacter sp., or even proteus sp., they can generally occur in both outpatients and inpatients. Most ordinarily occurring bacteria which is E. coli, can cause community or 
hospital-acquired infections $[1,2]$. The prevalence of these infections can be affected by factors such as age, immunosuppression, gender, and urological instrumentation [3]. Antibiotics must not be prescribed excessively, particularly in sight of the escalating prevalence of antibiotic resistance. Additionally, the infection initiated by the MDR strain of E. coli would boost the cost of treatment, morbidity, and mortality, specifically in countries such as India $[4,5]$. The antibiotic sensitivity patterns arising from these would differ from location to location. These MDR strains are often treated by several novel drugs that could be generated from the phytochemicals of the medicinally important plants.

These plants are presently believed to have a significant role in therapeutics because of their distinct properties to be used as drugs exclusively with the help of the extracted phytochemicals [6]. Phenolics and flavonoids, the commonly known phytochemicals from medicinal plants, have now been reported for building up immunity and health and preventing cancer or some other viral diseases [7]. For the past several decades, conventional medicinal plants have proven to sustain the biological, genetic diversity and their activity, including properties of antimicrobial, anticancer, antioxidant, antihypertensive, anti-diabetic, analgesics, etc. [8-10]. Phytochemicals viz., veronicoside, pikuroside, 4-hydroxy3-methoxy acetophenone, and various phenolic compounds are also determined in different extracts of $\mathrm{P}$. kurroa [11]. The present study is focused on the analysis of the antimicrobial Property of Picrorhiza kurroa (Kutaki) Against multidrug-resistant uropathogenic Escherichia coli. Kutaki, being one of the major incomes producing non-timber forest products of Nepal found in the Greater Himalayas, is the oldest medicinal plant traded from the Karnali Zone [6, 12]. Growing naturally in alpine ranges on rock scars as well as in organics soils, these plant parts in the different extract systems such that of methanolic or ethanolic solvents, have proven to reveal anti-bacterial activities against gram-positive bacteria (Bacillus subtilis, Staphylococcus aureus, and Micrococcus luteus) and also gram-negative bacteria (Escherichia coli and Pseudomonas aeruginosa) [13-15]. Despite various benefits that have been unrevealed in the present date, further research could be carried out to clarify the bioactive compounds and, most importantly, the phytochemicals extracted from medicinally important plants [12].

\section{Materials and Methods}

\subsection{Study design.}

The present study was carried out at the Department of Biotechnology, School of Basic and Applied Sciences, Shri Guru Ram Rai University, Dehradun, Uttarakhand. This analytical study of a urine sample from a patient suffering from Urinary Tract Infection (UTI) was performed to access the antimicrobial property of $P$. kurroa rhizome extract against the bacteria isolated. Ethical clearance was attained from the laboratory, and informed consent was taken from the patient.

\subsubsection{Urine sample collection.}

The urine sample was collected from DNA Labs- A Centre for Applied Sciences, Dehradun. History of the urine being of a 78-year-old patient suffering from Urinary Tract Infection, the patient had acute inflammation in the urethra. The collected urine sample was of a Dark yellowish color with a turbid appearance. The urine was firstly examined under the microscope at $45 \mathrm{X}$ magnification. 


\subsubsection{Plant sample collection.}

The plant sample included the rhizome part of the herb, which was long and woody; the identified sample was collected from the priest and ayurvedic medicine practitioner from Kedarnath, Uttarakhand. The plant part sample was of Picrorhiza kurroa, commonly known as Kedar Jadi or Kutaki in the local language of Kedarnath.

\subsection{Phytochemical extraction.}

The shed dried plant material was made into a fine powder using mortar and pestle. The dry powder was taken separately and was subjected to methanolic extraction, $500 \mathrm{ml}$ of $80 \%$ methanol was added to the $100 \mathrm{gm}$ of the dried plant powder sample and was kept at $80^{\circ} \mathrm{C}$ for 12 hours in a shaking incubator [9]. This method has been used in Ayurveda systems by the industries for ayurvedic medicine preparation from plant extracts. The solution was filtered to remove the solid portion or suspended particles and was collected in a glass beaker. The extracts obtained in the glass beaker were evaporated on a water bath and finally reduced thick viscous brownish-black extracts and transferred to previously weigh airtight glass container weighed on an electronic balance and stored in the refrigerator at $4{ }^{\circ} \mathrm{C}$ until further use. The phytochemical yield was determined by using the following formula:

$$
\text { Percentage of yield }=\frac{\text { Weight of Extract }(\mathrm{gm} .)}{\text { Weight of Powder Taken }(\mathrm{gm} .)} \times 100
$$

\subsection{Clinical bacterial isolation from a urine sample.}

The urine sample was taken in a sterilized container, $0.1 \mathrm{ml}$ of the sample of urine was spread over a nutrient agar plate (Beef extract: $3.0 \mathrm{~g}$, Peptone: $5.0 \mathrm{~g}, \mathrm{NaCl}: 5.0 \mathrm{~g}$; in $1000 \mathrm{ml}$ of water), and the plates were incubated at $36^{\circ} \mathrm{C}$ for 48 hours. After the incubation period, the plates were examined, and enumeration of bacterial colonies was done, an average of a triple set was taken.

\subsection{Partial identification via the clinical method.}

Gram staining was done of the isolated bacteria [16]. A small inoculum from the obtained colony of bacteria was streaked on a MacConkey agar media plate, which is a selective and differential media for isolation of gram-negative enteric bacteria based on lactose fermentation for the partial identification pathogen [17]. Escherichia coli causes most urinary tract infections, and few cases are caused by other pathogenic bacteria such as Klebsiella pneumoniae, Proteus mirabilis, Enterococcus faecalis, and Staphylococcus saprophyticus [18]. To partially identify and confirm the urine isolated UTI pathogen was done based on IMViC test, which included the Indole test, Methyl Red test, Voges-Proskauer test, and Citrate test [19].

\subsection{Antibiotic sensitivity test.}

The test performed was based on Kirby-Bauer procedure [20]. Antibiotic sensitivity test was done on the Muller Hinton agar plates, the composition of media was Beef infusion from: 300.00 gms, Casein acid hydrolysate: $17.50 \mathrm{gms}$, Starch soluble: $1.50 \mathrm{gms}$ and agar-agar powder $17.00 \mathrm{gms}$, all the ingredients were dissolved in $1000 \mathrm{ml}$ of distilled water and were 
autoclaved to sterilize the contents completely, the $\mathrm{pH}$ was maintained at 7.3 and plating was done followed by solidification of the media under aseptic conditions. A small inoculum was picked up and was made into a suspension of $0.9 \%$ sterilized normal saline. Sample from normal saline suspension was spread over MHA media plates by sterilized cotton swab; uniform spreading was done for even growth of the bacterial sample. 5 plates were prepared, and each plate was marked into 5 parts; in each part, one antibiotic disk was dispensed by a disk dispenser, and the attachment of the disk to the media surface was ensured. Total 26 antibiotics were used for the test, which is generally given in Urinary Tract Infection cases.

\subsection{Microbial inhibition test.}

To evaluate the antimicrobial assay of any plant or microbial extracts, the Agar well diffusion method is widely used [21]. Muller Hinton Agar (MHA) provides a uniform and controlled platform for the even diffusion of the plant extract; also, the bacterial sample grows evenly with a uniform surface over MHA Media [22].

The agar well diffusion method tested the crude phytochemical extract of Picrorhiza kurroa for its antimicrobial property. Microbial inhibition test was done on the Muller Hinton agar plates, the composition of media was Beef infusion from: 300.00 gms, Casein acid hydrolysate: $17.50 \mathrm{gms}$, Starch soluble: $1.50 \mathrm{gms}$ and agar-agar powder $17.00 \mathrm{gms}$, all the ingredients were dissolved in $1000 \mathrm{ml}$ of distilled water and were autoclaved to sterilize the contents completely, the $\mathrm{pH}$ was maintained at 7.3 and plating was done followed by solidification of the media under aseptic conditions. The isolated bacteria were grown in LuriaBertani broth, a suspension was made of the bacterial sample in $0.9 \%$ of sterilized normal saline solution, and inoculum from this solution was taken to spread over the prepared MHA media plates with the help of a sterilized cotton swab, the inoculum containing cotton swab was firstly streaked over the media surface gently, and then the plate was rotated to about 60 degrees, the process was repeated till the whole surface gets completely layered by the inoculum evenly, two plates were prepared.

A well of diameter $6.0 \mathrm{~mm}$ was made in the center of the media with the help of a sterilized media borer [23]. Of the two plates, one was labeled for the phytochemical antimicrobial test (PAT), in which well was filled with $100 \mu \mathrm{l}$ of extracted phytochemical of $P$. kurroa. The second plate was kept without the addition of phytochemical and was labeled as a control. The lids were replaced, and the prepared plates were then incubated for 24 hours at $36^{\circ}$ Celsius. Here, as a precaution, the plates shall not be inverted to avoid splashing of the phytochemical.

\section{Results and Discussion}

The microscopic examination of a urine sample under pathological results per $\mathrm{ml}$ of urine was: RBC: 5-6, Pus cells: 13-14, Epithelial Cells: 3-4, Crystals: nil and Bacteria: +++.

The bacterial colonies from the urine sample appeared on nutrient agar plates after 48 hrs of incubation as greyish white in color, large in size, round in shape with smooth edges, moist and opaque. After Gram Staining, the bacteria appeared as pink-colored, indicating gramnegative results, and were rod-shaped. The enumeration of colonies through CFU (Colony Forming Unit) count was greater than $10^{4} \mathrm{CFU} / \mathrm{ml}$ showing acute infection. Upon MacConkey agar, the streak colonies appeared as Pink in color, with the surrounding media surface darken in color. Further examination through IMViC Test is in Table 1. 
Table 1. IMViC Tests results of the isolated bacteria from urine sample.

\begin{tabular}{c|l|c} 
S.No. & TEST & RESULT $^{\#}$ \\
\hline 1. & Indole Test & + \\
\hline 2. & Methyl Red Test & + \\
\hline 3. & Voges-Proskauer Test & - \\
\hline 4. & Citrate Test & - \\
\#(+ $=$ Positive, - - Negative $)$ &
\end{tabular}

Therefore, based on the above results done for clinical identification of Uropathogens, it can be concluded that the isolated bacteria (uropathogenic) from the urine sample is Escherichia coli [19].

\subsection{Antibiotic sensitivity test.}

Among 26 Antibiotics used against the isolated E. coli strain to check resistivity or sensitivity, only 7 antibiotics were the bacteria sensitive rest for 19 antibiotics. It was resistant (Table 2); thus, it showed the isolated strain of E. coli is Multi-Drug Resistant (MDR).

Table 2. Antibiotic Sensitivity Test Results of the isolated uropathogenic E. coli.

\begin{tabular}{l|l|c|c|c} 
Antimicrobial Subclass & Antibiotics & $\begin{array}{c}\text { Power } \\
(\mathbf{m c g})\end{array}$ & Sensitivity & Zone $(\mathbf{m m})$ \\
\hline & Fosfomycin & 200 & $\mathrm{R}$ & \\
\hline & Ofloxacin & 5 & $\mathrm{~S}$ & $\mathbf{1 8}$ \\
\hline & Norfloxacin & 10 & $\mathrm{R}$ & \\
\hline & Nitrofurantoin & 300 & $\mathrm{~S}$ & $\mathbf{1 4}$ \\
\hline & Colistin & 10 & $\mathrm{R}$ & \\
\hline Penicillins & Ampicillin & 10 & $\mathrm{R}$ & \\
\hline & Piperacillin & 100 & $\mathrm{R}$ & \\
\hline & Ceftriaxone & 30 & $\mathrm{R}$ & \\
\hline & Cefixime & 5 & $\mathrm{R}$ & \\
\hline & Cefotaxime & 30 & $\mathrm{R}$ & \\
\hline B Lactamalosporins $/$ B Lactamase Inhibitor & Cefuroxime & 30 & $\mathrm{~S}$ & $\mathbf{1 8}$ \\
\hline & Cefepime & 30 & $\mathrm{R}$ & \\
\hline Carbapenems & Ceftazidime & 30 & $\mathrm{R}$ & \\
\hline & Cefazoline & 30 & $\mathrm{R}$ & \\
\hline & Amoxyclav & 30 & $\mathrm{R}$ & \\
\hline Aminoglycosides & Ampicillin- & $10 / 10$ & $\mathrm{R}$ & \\
\hline & Sulbactum & & $\mathrm{R}$ & \\
\hline Quinolones & Imipenem & 10 & $\mathrm{R}$ & \\
\hline & Meropenem & 10 & $\mathrm{R}$ & $\mathbf{1 9}$ \\
\hline Tetracycline & Ertapenem & 10 & $\mathrm{~S}$ & $\mathbf{1 9}$ \\
\hline & Gentamycin & 50 & $\mathrm{~S}$ & \\
\hline & Amikacin & 30 & $\mathrm{R}$ & \\
\hline & Ciprofloxacin & 5 & $\mathrm{R}$ & \\
\hline & Levofloxacin & 5 & $\mathrm{~S}$ & \\
\hline & Tetracycline & 30 & $\mathrm{R}$ & \\
\hline & Doxycycline & 30 & $\mathrm{R}$ & \\
\hline & & & & \\
\hline
\end{tabular}

\subsection{Antimicrobial assay of the plant extract.}

The methanolic extract after methanol evaporation was obtained in dark brown in color and viscous liquid form. 19.8 grams of the extract was obtained from 100 grams of the shadedried powdered root of $P$. kurroa through the methanolic extraction process, yielding $19.8 \%$ of yield according to the formula used. The E. coli strain was sensitive to phytochemical extract of P. kurroa. The Antimicrobial zone on the antimicrobial zone scale came out to be $23 \mathrm{~mm}$ (Figure 1), while there was uniform growth in the entire surface around the well of the control experiment plate (without phytochemical). 


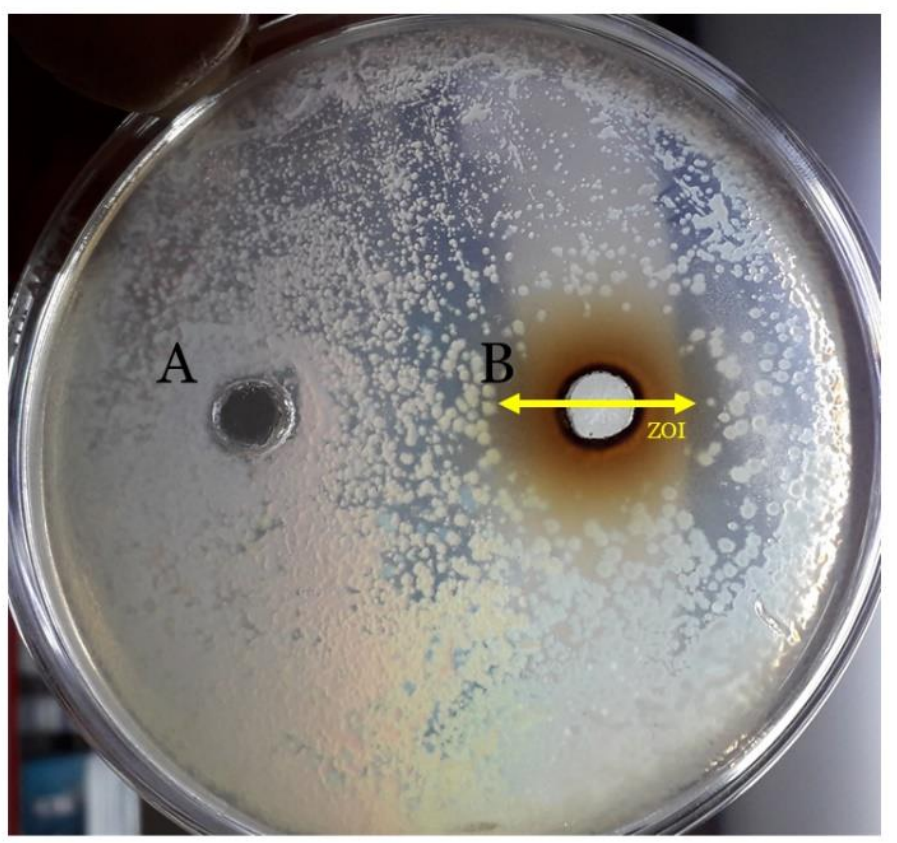

Figure 1. Antimicrobial assay wherein (A) represents Control well and (B) represents the well with phytochemical extract creating a zone of inhibition of $23 \mathrm{~mm}$.

\section{Conclusions}

The exposure of several antibiotic drugs to UTI patients is making the bacteria more Multi-drug Resistant. But these are not resistant to phytochemicals. Hence, the study of phytochemical science also referred to as the ancient technology of biochemical/ phytochemical sciences, is very informative and beneficial. All the medicinal plants or herbs contain phytochemicals in their extracts that could be extensively used for finding the cure of Urinary Tract Infections. Therefore, the medicinal plant Picrorhiza kurroa (Kutaki), a rare herb exclusively found in the Kedarnath or Badrinath region of the lush green Himalayas, can be used to obtain phytochemicals for treating UTI. The phytochemicals from these herbs can combat MDR Bacteria. In the present study, we had learned about E. coli bacteria, which was found resistant against 17 antibiotics out of the 26 antibiotics used. This work was only done in one methanolic extract, but further studies could be carried out using different concentrations of methanolic extract, and another solvent system can also be used for the research work of phytochemical assays. With these, we will be able to generate suitable medicine for UTI patients.

\section{Funding}

This research received no external funding.

\section{Acknowledgments}

Pallavi Dheer wishes to acknowledge the School of Basic, and Applied Sciences, Shri Guru Ram Rai University, Dehradun, Uttarakhand, and Siddhartha Dan wish to acknowledge the I.K Gujral Punjab Technical University, Jalandhar, Punjab, India, for carrying out this work.

\section{Conflicts of Interest}

The authors declare no conflict of interest. 


\section{References}

1. Villemagne, V.L.; Burnham, S.; Bourgeat, P.; Brown, B.; Ellis, K.A.; Salvado, O.; Szoeke, C.; Macaulay, S.L.; Martins, R.; Maruff, P.; Ames, D.; Rowe, C.C.; Masters, C.L. Amyloid $\beta$ deposition, neurodegeneration, and cognitive decline in sporadic Alzheimer's disease: a prospective cohort study. The Lancet Neurology 2013, 12, 357-367, https://doi.org/10.1016/S1474-4422(13)70044-9.

2. Sobel, J.D.; Kaye, D. Urinary tract infections. In: Mandell, Douglas and Bennett's Principles and Practice of Infectious Diseases. Mandell. G.L.; Bennett, J.E.; Dolin, R.; editors. 7th ed. Volume 1. Philadelphia, USA: Churchill Livingstone Elsevier Publication. 2010; pp. 958-72.

3. Bano, K.; Khan, J.; Begum, H.; Munir, S.; Akbar, N.; Ansari, J.; Anees, M. Patterns of antibiotic sensitivity of bacterial pathogens among urinary tract infections (UTI) patients in a Pakistani population. African Journal of Microbiology Research 2012, 6, 414-420.

4. Al-Jiffri, O.; El-Sayed, Z.M.F.; Al-Sharif, F.M. Urinary tract infection with Escherichia coli and anti-bacterial activity of some plants extracts. Int. J. Microbiol. Res 2011, 2, 1-7.

5. Iqbal, T.; Naqvi, R.; Akhter, S.F. Frequency of urinary tract infection in renal transplant recipients and effect on graft function. JPMA. The Journal of the Pakistan Medical Association 2010, 60, 826-829.

6. Fink, R.; Gilmartin, H.; Richard, A.; Capezuti, E.; Boltz, M.; Wald, H. Indwelling urinary catheter management and catheter-associated urinary tract infection prevention practices in Nurses Improving Care for Healthsystem Elders hospitals. American journal of infection control 2012, 40, 715-720, https://doi.org/10.1016/j.ajic.2011.09.017.

7. Thani, P.R.; Sharma, Y.P.; Kandel, P. Phytochemical studies on Indian market samples of drug "Kutki" Picrorhiza kurroa Royle ex Benth. Res. J. Agric. Forestry Sci. 2018, 6, 1-5, http://dx.doi.org/10.13140/RG.2.2.13113.26720.

8. Venugopal, R.; Liu, R.H. Phytochemicals in diets for breast cancer prevention: The importance of resveratrol and ursolic acid. Food Science and Human Wellness 2012, 1, 1-13, https://doi.org/10.1016/j.fshw.2012.12.001.

9. Webster, D.; Taschereau, P.; Belland, R.J.; Sand, C.; Rennie, R.P. Antifungal activity of medicinal plant extracts; preliminary screening studies. J Ethnopharmacol 2008, 115, 140-146, https://doi.org/10.1016/j.jep.2007.09.014.

10. Kang, C.G.; Hah, D.S.; Kim, C.H.; Kim, Y.H.; Kim, E.; Kim, J.S. Evaluation of antimicrobial activity of the methanol extracts from 8 traditional medicinal plants. Toxicological research 2011, 27, 31-36, https://doi.org/10.5487/tr.2011.27.1.031.

11. Rautela, I.; Dheer, P.; Thapliyal, P.; Joshi, T.; Sharma, N.; Sharma, M. GC-MS Analysis Of Plant Leaf Extract Of Datura Stramonium In Different Solvent System. European Journal of Biomedical and Pharmaceutical Sciences 2020, 5, 236-245.

12. Sharma, N.; Pathania, V.; Singh, B.; Gupta, R.C. Intraspecific variability of main phytochemical compounds in Picrorhiza kurroa Royle ex Benth. from North Indian higher altitude Himalayas using reversed-phase highperformance liquid chromatography. Journal of Medicinal Plants Research 2012, 6, 3188-3192.

13. Debnath, P.; Rathore, S.; Walia, S.; Kumar, M.; Devi, R.; Kumar, R. Picrorhiza kurroa: a promising traditional therapeutic herb from higher altitude of western Himalayas. Journal of Herbal Medicine 2020, 23, https://doi.org/10.1016/j.hermed.2020.100358.

14. Kumar, P.V.; Sivaraj, A.; Madhumitha, G.; Saral, A.M.; Kumar, B.S. In-vitro anti-bacterial activities of Picrorhiza kurroa rhizome extracts using agar well diffusion method. Int. J. Curr. Pharmaceut. Res. 2010, 2, 30-33.

15. Rathee, D.; Rathee, P.; Rathee, S.; Rathee, D. Phytochemical screening and antimicrobial activity of Picrorrhiza kurroa, an Indian traditional plant used to treat chronic diarrhea. Arabian Journal of Chemistry 2016, 9, S1307-S1313, https://doi.org/10.1016/j.arabjc.2012.02.009.

16. Usman, M.R.M.; Surekha, Y.; Chhaya, G.; Devendra, S. Preliminary screening and antimicrobial activity of Picrorhiza kurroa royle ethanolic extracts. Int J Pharm Sci Rev Res 2012, 14, 73-76.

17. Colco, R. "Gram Staining". Current Protocols in Microbiology. 00 (1): Appendix 3C, 2005; https://doi.org/10.1002/9780471729259.mca03cs00.

18. Anderson, C. Great Adventures in the Microbiology Laboratory. 7th ed. 2013; Pearson. pp. 175-176.

19. Tabibian, J.H.; Gornbein, J.; Heidari, A.; Dien, S.L.; Lau, V.H.; Chahal, P.; Churchill, B.M.; Haake, D.A. Uropathogens and host characteristics. Journal of clinical microbiology 2008, 46, 3980-3986.

20. Vihari, S.; Laeeq, S.; Pradhan, R.; Khan, I. Identification Of Microbial Flora From Uti Patients Via Biochemical Reactions. International Journal of Current Research 2014, 6, 9028-9037.

21. Hudzicki, J. Kirby-Bauer Disk Diffusion Susceptibility Test Protocol Created. Tuesday, 08 December, 2009.

22. Caron, F. Antimicrobial susceptibility testing: a four facets tool for the clinician. J. Des. Anti-Infect. 2012, 14, 186-174.

23. Hendriksen, R.S. Susceptibility testing of Salmonella using disk diffusion. World Health OrganizationWHO: USA 2002; pp. 9.

24. Magaldi, S.; Mata-Essayag, S.; De Capriles, C.H.; Perez, C.; Colella, M.T.; Olaizola, C.; Ontiveros, Y. Well diffusion for antifungal susceptibility testing. International journal of infectious diseases 2004, 8, 39-45. 